\title{
A RESTRIÇÃO DO DIREITO FUNDAMENTAL DE PROPRIEDADE: UMA ANÁLISE A PARTIR DA ALTERLOGIA
}

\section{Joel Meireles Duarte1* Caroline dos Santos Chagas2**}

\section{RESUMO}

A restrição ao direito fundamental de propriedade, a partir da alterlogia, é a temática deste artigo, que trata do direito de propriedade e do conceito da alteridade e alterlogia, questionando-se a possibilidade de restrição do direito de propriedade, fundado na moralidade relacional "eu-outro". Para tanto, serão realizadas considerações sobre alteridade, alterlogia, restrições aos direitos fundamentais, finalizando com a restrição ao direito de propriedade fundado na alterlogia, concluindo-se pela possibilidade de intervenção no direito de propriedade fulcrado na alteridade, utilizando de publicações de periódicos, artigos científicos, dissertações e teses sobre o tema, bem como, a pesquisa bibliográfica e documental.

Palavras-chave: Direitos Fundamentais; Direito de Propriedade; Intervenção no Direito de Propriedade; Alteridade; Alterlogia.

\section{RESTRICTION OF FUNDAMENTAL PROPERTY RIGHT: AN ANALYSIS FROM ALTERLOGY}

\begin{abstract}
The restriction to the fundamental right to property, from alterlogy, is the theme of this article, which deals with the right to property and the concept of alterity and alterlogy, questioning the possibility of restricting the right to property, based on relational morality "I-other". For this purpose, considerations will be made on alterity, alterlogy, restrictions on fundamental rights, ending with the restriction to property rights based on alterlogy, concluding by the possibility of intervention in property rights based on alterity, using journal publications, articles scientific, dissertations and theses on the subject, as well as bibliographical and documentary research.
\end{abstract}

Keywords: Fundamental Rights. Property Right. Intervention in Property Rights. Alterity. Alterlogy.

1 Mestrado em Planejamento Territorial e Desenvolvimento Social pela Universidade Católica do Salvador (2017). Advogado e Coordenador Jurídico da Primeira Secretaria da Assembleia Legislativa do Estado da Bahia (ALBA). joelmeireles@live.com. https://orcid.org/0000-0001-5403-1345

2 Advogada, pós-graduada em Direito Civil, Comercial e do Consumidor pela Associação Unyhana. Mestranda em Direitos Fundamentais e Alteridade pela Universidade Católica de Salvador. carolinechagas.adv@ gmail.com. http://orcid.org/0000-0002-9328-8423 


\section{INTRODUÇÃO}

O direito de propriedade é um direito fundamental do indivíduo que, assim como outros direitos fundamentais individuais e coletivos, deve ser resguardado pelo Estado.

O estudo da efetivação dos direitos fundamentais e, mormente, o de sua restrição, cumprem papel de elevada relevância e, simultaneamente, gerador de incansáveis debates doutrinários, tendo em vista as diferentes concepções apresentadas entre os estudiosos deste campo.

Neste sentido, apresenta-se o estudo da alterlogia, nova lógica da ação apresentada por Maria do Céu Patrão Neves (2017), através da qual se tem o descentramento do eu em favor do outro, enquanto limitante de direitos, com o fito de identificar a possibilidade de se restringir o direito fundamental de propriedade com justificativa na alteridade.

O presente trabalho aborda a temática, trazendo o escopo de estudar lições doutrinárias, para responder ao seguinte questionamento: pode-se restringir o direito fundamental de propriedade, a partir da moralidade das relações humanas entre o "eu" e o “outro" enquanto titulares de direitos e deveres?

Para atingir o fim acima delineado, incursiona-se, no primeiro capítulo, pelo conceito de alteridade e alterlogia segundo as lições de Maria do Céu Patrão Neves (2017), bem como, um apanhado do temos na visão de outros doutrinadores.

No segundo capítulo apresentam-se lições doutrinárias acerca das restrições a direitos fundamentais, do direito fundamental de propriedade, sua origem segundo Engels (2019) e, ainda, sobre sua possível limitação, para, então, adentrar no ponto do central do presente artigo.

Assim, no terceiro capítulo discute-se a possibilidade de se intervir e limitar o direito fundamental de propriedade a partir da alterlogia.

No que concerne à metodologia, a presente pesquisa parte do pressuposto que a unicidade metodológica não é apta a alcançar o desenvolvimento científico vivenciado atualmente.

No tocante a metodologia desta pesquisa, utilizar-se-á, o método cartesiano defendido por René Descartes (2007), partindo das ideias mais gerais para, gradativamente, efetuar uma análise dos objetos mais específicos. 
Em tempo, far-se-á a utilização como método de abordagem qualitativa, segundo o qual, o pesquisador procura-se entender acerca do fenômeno que é observado.

Em breves linhas, sob a ótica do método qualitativo, o pesquisador o analisa os dados inserido num cenário natural, a fim de interpretar o seu significado, explorando suas ideias e preocupações sobre o tema, e por fim, alcançando uma conclusão.

Destarte, para a materialização da presente pesquisa, buscou-se a utilização de fontes de pesquisa bibliográficas e documentais, decorrente do cunho hegemonicamente doutrinário das premissas acerca do panorama de estudo proposto, recorrendo-se às doutrinas nacionais e estrangeiras para tratar dos aspectos constitucionais e de direitos fundamentais atrelados à alteridade a alterlogia, bem como, ao direito fundamental de propriedade.

\section{ALTERIDADE E ALTERLOGIA}

Considerada como paradigma da moralidade das relações humanas, a alteridade em sua concepção hodierna exprime a ideia de que "somente a ética resgata o outro ao eu".

As lições de Levinas expressam exatamente essa acepção de "respeito ao outro", quando o outro será sempre o ponto de partida, fazendo-se desse um ideal regulador dos espaços de construção democrática, através do qual a "não-indiferença e responsabilidade para com o outro" fundamentam a existência política por intermédio da ética da alteridade Leviniana (COSTA, 2013, p. 82).

Como Explica José André da Costa, "Levinas fala de um novo saber, um conhecimento que não faz parte do sujeito ou que se unifica no sujeito, mas a uma forma de conhecimento que se dá na relação com o outro [...]” (COSTA, 2013, p. 91).

Bem assim, quando se refere ao "outro", não se fala mais em igualdade propriamente dita, mas sim no respeito à sua condição de "outro", à sua diversidade, protegendo-o enquanto tal, para que a relação "eu-outro" se estabelece em reciprocidade atrelada à concepção de alteridade, que, por sua vez reflete ilações necessárias à coexistência quotidiana (NEVES, 2017, p. 80).

Nesse mesmo sentido, as lições de Reynaldo Soares da Fonseca (2019, p. 33) demonstram que é justamente a ética transbordada em alteridade que transforma a concepção de política e direitos possíveis através da relativização da autonomia do ser e abertura para a 
sociabilidade, por um conceito de "fraternidade próximo à não-indiferença universal para com o outro[...]" (FONSECA, 2019, p. 33).

Nesse contexto, Eduardo Bittar (2009, p. 553) entende como legítimo “[...] pensar no reconhecimento da diferença e da peculiaridade de uma minoria, mais do que na pressuposição da igualdade genérica de todos.” (BITTAR, 2009, p. 553).

Sendo que a ampliação do conceito de direito, abrangendo o direito à diferença, “[ ...] consolida a ambição de diferenciação, dentro de sociedades modernas que tendem a produzir homogeneização e padronização [...]" (BITTAR, 2009, p. 553).

Por isso, citando Honneth, Bittar (2009, p. 553) explica que a noção de dignidade está intimamente atrelada tanto ao reconhecimento da igualdade jurídica, quanto no reconhecimento da diferença.

Para o autor, "o direito à diferença está baseado na ideia de que todos são diferentes entre si [...]" (BITTAR, 2009, p. 555).

Porém, há de se respeitar a natureza humana e, por esta, todos temos algo em comum, que é atrelado ao respeito à alteridade e, portanto, "todos são pertencentes à comunidade dos que fruem de direitos, na medida concreta de sua condição.” (BITTAR, 2009, p. 555).

Assim, Bittar (2009, p. 555) conclui que é imprescindível que as sociedades contemporâneas promovam e permitam o igual acesso ao reconhecimento.

Portanto, “[...] não existe alteridade sem diversidade [...]” (BITTAR, 2009, p. 555), o que exige uma visão de mundo descentrada, que, nas lições de Neves (2017, p. 70), encontramos situados no campo da alterlogia.

\subsection{O DESENVOLVIMENTO CONCEITUAL SEGUNDO AS LIÇÕES DE MARIA DO CÉU PATRÃO NEVES}

Maria do Céu Patrão Neves (2017, p. 70), ensina que o termo alteridade deriva, no latim, de alteritas, que significa diversidade, diferença, enquanto possui em sua raiz o adjetivo alter, que significa outro, um de dois.

Sendo assim, na etimologia da palavra, alteridade reflete a concepção de ser outro num cenário de diversidade. (NEVES, 2017, p. 70)

$\mathrm{Na}$ abordagem conceitual do termo, Neves (2017, p. 71) apresenta a alteridade em suas concepções ontológicas, gnosiológica e antropológica. 
No contexto da ontologia, a alteridade surge na Antiguidade Clássica como uma designação de ser distinta, "em função de uma identidade e numa relação de oposição". (NEVES, 2017, p. 71)

Assim, explica Neves (2017, p. 71): “[...] o 'outro’ que a alteridade exprime, é um ser, é um modo de ser distinto daquele que o define como tal, contrapondo-se lhe num contexto dicotômico de inteligibilidade que o define como outro [...]" e, desse modo, "[...]como inferior a si na hierarquia dos seres [...]" (NEVES, 2017, p. 71).

Decerto, porém, que a concepção ontológica de alteridade não afeta a moralidade das relações humanas porquanto estabelece realidades qualitativas distintas (NEVES, 2017, p. 72).

Na perspectiva gnosiológica, por sua vez, “[...] é o sujeito do conhecimento que se pronuncia sobre a realidade do outro [...]" e, assim, é quem define a realidade do outro, o que “[...] apenas permite estabelecer um sentido unívoco da relação que, como tal, permanece inacabada, incompleta[...]” (NEVES, 2017, p. 72).

Por esta razão, a autora explica que em nenhuma destas perspectivas a realidade do outro que a alteridade exprime, adquire a devida relevância. De sorte que, é na perspectiva antropológica que a concepção de alteridade se verifica presente na moralidade e eticidade das relações humanas.

Constituída apenas na contemporaneidade, a antropologia se exprime no estudo da relação eu-outro e, através dessa disciplina é possível extrair o significado de alteridade atinente à relação dos homens e à organização das sociedades contemporâneas (NEVES, 2017, p. 73).

Por este motivo, afirma-se que alteridade é um conceito de natureza essencialmente ética e índole antropológica, que exprime a relação entre o eu e o outro na sua constituição recíproca (NEVES, 2017, p. 80).

\subsection{A ALTERLOGIA ENQUANTO UMA "NOVA LÓGICA DA AÇÃO”}

Para Neves (2017, p. 81), a concepção de alteridade perpasse necessariamente numa nova lógica da ação, decorrente da alteridade como "alterlogia", através da qual se tem o descentramento do "eu" na sua relação com o "outro" e o respeito pelo outro na sua afirmação em si. 
$\mathrm{Na}$ ótica da autora, a alterlogia "[...] consiste numa nova coerência do nosso pensamento e, sobretudo, da nossa ação, fundamentada e estruturada a partir da afirmação da presença originária, constante e indelével do outro e, ainda integrada e constituinte do eu." (NEVES, 2017, p. 81).

O reconhecimento do outro e dos direitos do outro tomou expressão apenas na contemporaneidade e num cenário de liberalidade dos direitos (NEVES, 2017, p. 81).

Todavia, não se pode querer que a realização da necessidade de um, dependa da boa vontade do outro. Ao tempo em que, facultar a cada um as próprias escolhas é considerada a melhor garantia de ser feliz (NEVES, 2017, p. 81).

Na lógica da alterlogia, porém, se determina uma nova direção da ação no que se refere ao atual enquadramento das relações humanas estruturadas pelos direitos e deveres que competem a cada um.

Isso porque, para Neves (2017, p. 83), o estabelecimento de direitos em muito contribuem para o individualismo que, por vezes, “[...] se torna autoritário, prepotente e mesmo agressivo[...]".

Nesse mesmo sentido, diz-se que as normas de direito fundamentais se tornam apenas simbólicas pois, apesar de declaradoras de direito, na prática se tornam protelatórias e capazes de dissimular movimentos sociais.

Por este motivo:

[...] tanto o descentramento do eu como respeito pelo outro são indispensáveis na alterlogia, mas nenhum pode ser procurado individual e separadamente, o que ora tende a suprimir um dos polos da relação (altruísmo), ora mantém a dicotomia entre o eu e o outro (libertarismo), quando só a reciprocidade é ética. (NEVES, 2017, p. 83)

Dessa forma, pela alterlogia, exigir-se-á uma dupla inversão na relação de direitos e deveres, para que haja primordialidade dos deveres em relação aos direitos e uma proporcionalidade indireta entre deveres e direitos.

Assim, a alterlogia "[...] procede à inversão total da lógica preponderante nas sociedades contemporâneas focadas numa atribuição sempre crescente de direitos." (NEVES, 2017, p. 84).

Apesar disso, a lógica do direito hodierna se funda na premissa da liberdade individual e “[...] não se articula com os requisitos da alteridade.” (NEVES, 2017, p. 84). 
Enquanto a lógica exigida pela alteridade se funda nas obrigações ou responsabilidades que competem na relação do eu com o outro (NEVES, 2017, p. 84).

Como explica a professora, a assunção da alteridade e da alterlogia na prática é "extraordinariamente exigente e de difícil, senão mesmo de impossível concretização nas nossas sociedades coetâneas.” (NEVES, 2017, p. 85).

\section{AS RESTRIÇÕES A DIREITOS FUNDAMENTAIS E O DIREITO FUNDAMENTAL DE PROPRIEDADE}

Primeiramente, considerando que o presente trabalho pretende estudar a possibilidade de se restringir o direito fundamental de propriedade a partir da alterlogia, é mister introduzir ensinamentos acerca das restrições a direitos fundamentais.

Robert Alexy (2008, p. 276) afirma que "[...] direitos tenham restrições e que possam ser restringidos, parece ser uma ideia natural[...]".

Contudo, para ele, o problema reside em definir possíveis "[...] conteúdo e extensão dessas restrições e nas distinções entre restrição e outras coisas como regulamentações, configurações e concretizações[...]” (ALEXY, 2008, p. 276).

Para o autor (ALEXY, 2008, p. 281), "[...] restrições a direitos fundamentais são normas que restringem uma posição prima facie de direito fundamental[...]" e, assim, esclarece que as restrições a direitos fundamentais são normas.

Sendo de vital importância destacar que:

"[...] restrições diretamente constitucionais são somente as normas de hierarquia
constitucional. Na medida em que a cláusula 'ordem constitucional' permite a
restrição por meio de normas infraconstitucionais, ela é uma cláusula de reserva: ela
confere poderes ao legislador para estabelecer restrições indiretamente
constitucionais." (ALEXY, 2008 p. 286)

Porém, Alexy (2008, p. 282) destaca que somente se pode considerar como uma restrição a um direito fundamental, se essa "norma" for compatível com a Constituição porquanto, sendo inconstitucional, haveria uma intervenção no direito fundamental discutido, mas não uma restrição.

Nesse sentido, o escritor alemão assevera: 
[...] é preciso distinguir as competências para a criação de normas que são fundamentais pelas reservas legais constitucionais - competências diretamente estabelecidas pela Constituição - das competências constitucionais indiretas, que surgem, por exemplo, quando o legislador autoriza a edição de atos normativos . (ALEXY, 2008, p. 282)

Isto porque, as "[...] normas de competência não restringem os direitos fundamentais, apenas fundamentam sua restringibilidade. Por isso, as reservas legais não são enquanto tais, restrições.” (ALEXY, 2008, p. 282).

Sendo assim, apoiando-se nas lições de Peter Lerche, Alexy explica que existe:

[...] também a lei autorizadora como 'norma interventora', isto é correto na medida em que uma autorização para o estabelecimento de restrições, a qual sempre é uma autorização para uma intervenção, é algo potencial e indiretamente restritivo ou interventivo, no sentido acima. (ALEXY, 2008, p. 282)

Sendo que as normas mandatórias, proibitivas, bem como as que "[...] restrinjam ou elimine a competência dos cidadãos [...]" (ALEXY, 2008, p. 282), pois, continua o "[...] caráter restritivo das normas mandatórias e proibitivas é também aplicável, em sua essência, a outras espécies de normas.” (ALEXY, 2008,p. 283).

\subsection{A INGERÊNCIA POR PARTE DO ESTADO}

Segundo Bodo Pieroth (2019, p. 123), o exercício pleno e espontâneo das liberdades dos titulares de direitos fundamentais poderia conduzir a conflitos face ao interesse da coletividade e das próprias liberdades individuais de outros titulares de direitos fundamentais e por este motivo é que existem as ingerências

O escritor explica que:

[...] verifica-se uma ingerência, um limite, uma limitação ou restrição, uma afetação, uma redução ou uma delimitação por parte do Estado sempre que o particular é por este impedido de ter uma conduta abrangida pelo âmbito de proteção de um direito fundamental. (PIEROTH, 2019, p. 124)

Por sua vez, não se pode permitir um cenário em que o Estado aja de forma injustificada e desmedida na limitação do direito fundamental do particular. 
Assim, estabelecem-se os limites de limites, que são "[...] as limitações que o legislador está sujeito quando estabelece fronteiras ao exercício dos direitos fundamentais." (PIEROTH, 2019, p. 142).

Considerando como mais importante limite de limites, a proporcionalidade, exige-se do Estado que: o emprego do meio para alcançar o fim seja adequado; e que o emprego do meio para atingir o fim seja necessário (PIEROTH, 2019, p. 143).

\subsection{O DIREITO FUNDAMENTAL DE PROPRIEDADE}

\subsubsection{A ORIGEM DA PROPRIEDADE PRIVADA SEGUNDO ENGELS}

Em suas lições, Friedrich Engels (2019) apresenta a origem e evolução da família para destacar o marco que considera a origem da propriedade.

Em que pese este não seja o objeto central do presente artigo, faz-se necessário um pequeno adendo acerca da gens no período da Barbárie e da Civilização, para então situar a origem da propriedade em Engels.

Considerando os exemplos dos gregos, romanos e germanos, a gens enquanto evolução do formato de família surge no estágio superior do estado selvagem e atinge o período áureo no estágio inferior da Barbárie. (ENGELS, 2019, p. 147)

Segundo Engels (2019, p. 147), a gens ou também gentes, advém da ramificação de uma tribo em várias gentes distintas que, com o crescimento populacional, se subdivide em novas e diversas gentes-filhas, unidas por relações de parentesco às gens originárias.

Para o autor, nada mais é que um agrupamento próprio, nascido naturalmente, e capaz de resolver todos os conflitos que podem surgir dentro da sociedade organizada dessa maneira.

Historicamente, as posses e propriedades não eram privadas, mas sim comuns no âmbito familiar, inclusive dentro das próprias gens (ENGELS, 2019, p. 148).

Todavia, com o aprofundamento dessa mudança no formato de família e a consequente dispersão, cada indivíduo passa a ser proprietário das ferramentas que confecciona e usa, enquanto o que é feito e usado em conjunto, é propriedade comum, onde, para Engels (2019, p. 148), se aplica a “[...] propriedade pessoalmente processada[...]” como tida na sociedade civilizada. 
Em diversos lugares os indivíduos vinculados às gens não permaneceram estagnados nesses estágios, e passaram a criar individualmente animais como o gado, fazendo disso seu principal ramo de trabalho, com a horticultura e produção de outros meios de subsistência (ENGELS, 2019, p. 148).

Com a evolução desse novo formato social, os rebanhos e terras que originalmente eram propriedades das gens, passaram a ser propriedade especial (leia-se, propriedade privada) daqueles que os mantinham, de sorte que os indivíduos passaram a ter certos direitos de posse sobre as terras, mas, até aquele momento, somente isso. (ENGELS, 2019, p. 149)

Em que pese não consiga identificar exatamente em qual momento surgiu a propriedade privada plena, Engels (2019, p. 149) entende que a passagem da propriedade comum para a propriedade especial (leia-se, novamente, privada) se deu exatamente nesse estágio de revolução da família, quando os rebanhos eram os novos meios de subsistência e, assim, enquanto a domesticação e manutenção era tarefa do homem, a ele pertencia o gado.

Com isso, a família individual tomou força e passou a ameaçar a concepção de gens, de sorte que o acumulo de riquezas e as diferenciações sociais entre os chefes das famílias individuais acabaram por implodir a comunidade doméstica comunista (ENGELS, 2019, p. 151).

Com isso, também o cultivo comunitário do solo, de sorte que a propriedade passa a ser transferida e aproveitada pela família individual pouco a pouco, até que a propriedade privada se consolida como tal, paralelamente à monogamia, entre o estágio intermediário da barbárie e o limiar da civilização (ENGELS, 2019, p. 151).

Com o advento da civilização, diferentemente daquela posse inicialmente entregue pela gens em favor do indivíduo, essa propriedade plena e livre do solo conferia além da posse irrestrita, o direito de venda.

Por este motivo, Engels (2019, p. 152) entende a civilização como o estágio de desenvolvimento da sociedade em que a divisão do trabalho e a troca de produtos e mercadorias revolucionam a sociedade antiga, posto que os produtores são agora tidos como donos do processo e do produto.

Citando Marx, Engels destaca que esta consumação da propriedade privada jamais teria ocorrido se "[...] a diferença de propriedade dentro da própria gens não tivesse transformado a unidade dos interesses em antagonismo dos integrantes da gens." (ENGELS, 2019, p. 152). 


\subsubsection{A PROPRIEDADE ENQUANTO DIREITO FUNDAMENTAL}

Lothar Michael (2016, p. 320 e 321) entende a propriedade como uma liberdade do indivíduo que o torna independente e livre para o exercício de outros direitos de liberdade e, como tal, seu valor econômico pode ser garantidor da subsistência pessoal do indivíduo, de sorte que deve haver proteção social da propriedade.

"Propriedade", para o autor, é conjunto de todos os direitos de valor patrimonial e de direito privado que abrangem não apenas as pretensões absolutas e reais, como também às relativas à sua livre utilização. (MICHAEL, 2016, p. 325)

Como assevera Bodo Pieroth (2019, p. 437), a garantia do direito de propriedade tem o condão de resguardar ao titular desse direito fundamental um espaço de liberdade que lhe possibilite "[...] uma organização autorresponsável da sua vida."

Nesse mesmo sentido, Ana Prata (2017, p. 135) apresenta um estudo da tutela da autonomia privada como tutela da propriedade, esclarecendo que um dos aspectos atinentes ao direito de propriedade são as faculdades integradas a este, como o gozo e a disposição.

Acerca do gozo, porém, a autora afirma que o direito pode sofrer restrições (PRATA, 2017, p. 143).

\subsection{LIMITES E RESTRIÇÕES AO DIREITO FUNDAMENTAL DE PROPRIEDADE}

Enquanto direito fundamental, a garantia de existência da propriedade deve ser protegida de ingerências do Estado também no que tange à sua utilização, de forma que ao proprietário deverá ser garantido não apenas a manutenção de sua propriedade, mas também o uso, fruição e disposição desta.

Contudo, a propriedade perde essa proteção quando utilizada para ações que são proibidas e somente quando se vislumbra a função social nas ações que permeiam a propriedade é que se aplicam as proteções contra as ingerências (PIEROTH, 2019, p. 445).

Aludidas restrições têm o fito de impor limitação à atuação dos proprietários para garantir o exercício do direito de toda a coletividade, o que nos remete às lições iniciais de Ana Prata acerca da intervenção do Estado na autonomia privada como sucedâneo de uma 
pressão de certas necessidades e sua satisfação, função que se incumbe por lei e, prioritariamente, pela Constituição (PRATA, 2017, p. 39).

Conquanto a própria constituição prescinda de uma definição específica do direito e conceito de propriedade, diz-se que o legislador é obrigado a criar "[...] um quadro para posições de propriedade e a manter essas funcionais [...]", bem como, submete-se necessariamente à proporcionalidade nas hipóteses em que se faça necessário conformar ou limitar os direitos de propriedade (MICHAEL, 2016, p. 323).

Maria Sylvia Zanella di Pietro (2012 p. 130) explica que a propriedade, enquanto mais amplo direito real que abrange a garantia do uso, gozo e disposição da coisa, de forma absoluta, evoluiu da concepção individual para concepção social a partir da Revolução Francesa.

O código napoleônico consagrou a propriedade como o "[...] direito de gozar e de dispor das coisas de modo absoluto, contanto que isso não se torne proibido pelas leis ou pelos regulamentos [...]” (DI PIETRO, 2012, p. 130).

O que se pode observar é que, em que pese o direito de propriedade seja um direito fundamental, não se pode permitir que seja exercido ilimitadamente, ferindo direitos alheios que coexistam ou sufocando o interesse público maior, cuja tutela cabe ao Poder Público (DI PIETRO, 2012, p. 132).

Quando se impõe obrigações de caráter geral a proprietários indeterminados, em benefício do interesse geral, afetando o caráter absoluto do direito de propriedade tem-se as chamadas limitações administrativas (DI PIETRO, 2012, p. 131)

Citando Bielsa, Di Pietro (2012, p. 131) esclarece que as limitações administrativas possuem 3 características fundamentais: impõem obrigação de não fazer ou deixar fazer; só se estendem até onde a necessidade se verifique; e não dão direito à indenização.

\section{A RESTRIÇÃO AO DIREITO FUNDAMENTAL DE PROPRIEDADE A PARTIR DA ALTERLOGIA}

José Querino Tavares Neto e Katya Kozicki (2008, p. 66) entendem a política e a democracia como devir ético e, aproximando-se ética, direito e política, adotam como premissa uma ética não universalista e fundada na ideia de alteridade, na qual o outro aparece como categoria central. 
Por este motivo, uma sociedade mais justa e coerente carece, necessariamente, da alteridade (NETO e KOZICKI, 2008, p. 67).

Partindo dessa premissa, os autores explicam que o Estado é quem desempenha a função de garantir a convivência ordenada entre os homens, entre o eu e o outro (NETO e KOZICKI, 2008, p. 66).

Como explicam Nilton Cesar Flores e José Carlos F. Bortoloti (2013), é de suma importância que o Estado proporcione positivamente um projeto voltado ao desenvolvimento humano, que preste uma estrutura ao indivíduo para que busque realizar seus direitos como parte constituinte da sociedade, iniciando-se, também:

[...] um processo interpretativo e intersubjetivo que parte diretamente das relações humanas e condiciona a possibilidade da realização plena dos direitos humanos a partir da alteridade positiva. (FLORES e BORTOLOTI, 2013, p. 127 e 129)

E dessa forma:

[...] a alteridade se confirma como instrumento de desvelamento, como o resgate da necessária ponderação do humanismo do outro homem para que os direitos humanos (e fundamentais) consigam ter seu fundamento e empirismo com a análise das relações que constroem o social. (FLORES e BORTOLOTI, 2013, p.125)

Alteridade, por sua vez, somente se concretiza por meio de um compromisso ético com a justiça e o reconhecimento de uma infinita responsabilidade para com o outro, sem que o reconhecimento das diferenciações implique em negligência ética ou indiferença moral (NETO e KOZICKI, 2008, p. 68).

Considerando que os direitos fundamentais são frutos de conquistas históricas dos mais diversos setores da sociedade, os autores os tratam não como concessão, mas sim como emancipação.

Todavia, a despeito de considerar "[...] os direitos fundamentais positivados como inalienáveis, apesar de não absolutos [...]", estes precisam ser tratados de forma paradigmática e limitadora, para que, na perspectiva da alteridade, sabermos que esses direitos devem ser relativizados em sua pretensa universalidade (NETO e KOZICKI, 2008, p. 71).

Nesse cenário, o Estado seria o principal articulador dos processos de conscientização e efetivação dos direitos humanos e fundamentais, tendo a alteridade como referencial hermenêutico. 
Assim, tem-se que a alteridade deve ser pressuposto de organização das relações humanas e de direitos fundamentais atrelados à própria existência do homem enquanto sujeito de direito, de modo que a coexistência social em uma comunidade não implique a negação da individualidade, mas respeite a existência do outro.

A propriedade, enquanto direito fundamental, apesar de ser consagrada um direito individual, é considerada como princípio da ordem econômica.

Eros Roberto Grau (2018, p.229 e 233) esclarece que a propriedade privada e a função social da propriedade são consideradas princípios da ordem econômica pelo inciso II, do art. 170, da Constituição Federal Brasileira de 1988, porquanto se trata de instrumento a garantir a subsistência individual e familiar e, assim, a própria dignidade da pessoa humana.

Apesar de considerar a propriedade privada e sua função social como princípios de ordem econômica, o Autor (GRAU, 2018, p.191) explica que, à ordem econômica, importa considerar a dignidade da pessoa humana, ao lado do direito à vida, como núcleo essencial dos direitos humanos.

Quando se diz, portanto, que a sociedade deve cumprir sua função social, quando o eu, titular do direito de propriedade, ignora, viola ou não respeita o outro, descumprindo a função social da propriedade, se consagra a possibilidade de intervir na propriedade pela concepção de alteridade, sob a nova lógica de ação, a alterlogia.

\section{CONCLUSÃO}

Diante do que aqui se expôs, pode-se observar que a alteridade, intimamente ligada a diversidade, prevê o estabelecimento de uma relação ética entre o eu e o outro, através da qual existe o reconhecimento do outro.

Essa concepção de alteridade, por sua vez, exprime nas lições de Maria do Céu Patrão Neves (2017) uma lógica da ação denominada alterlogia, através da qual se tem a fuga da centralização no eu na relação com o outro, que resulta no respeito pelo outro na sua afirmação em si e no reconhecimento dos direitos do outro.

Como se viu das lições de Robert Alexy (2008), direitos fundamentais são passíveis de restrições, justamente porque não podem ser executados de forma a obstar a realização de outros direitos fundamentais. 
Sendo assim, sempre que se fizer necessário, respeitando-se a proporcionalidade enquanto limite, caberá ao Estado intervir no amplo gozo de um direito fundamental em prol da efetivação de outro.

Em que pese, como asseveraram Neves (2017), Tavares Neto e Kozicki (2008), a nova lógica da ação da alterlogia, advinda da alteridade, seja extraordinariamente exigente e de difícil na sociedade contemporânea, é possível observar instrumentos através do qual o Estado intervém no direito do eu em prol do direito do outro.

No que tange ao direito de propriedade, a título de exemplo, é possível observar tal restrição através da Desapropriação Sancionatória.

A propriedade, enquanto direito fundamental do eu, não mais se considera um direito absoluto, mas se conforma à função social e não pode prevalecer sobre o direito fundamental do outro quando desrespeitadas as premissas da reciprocidade moral nas relações humanas, porquanto estas norteiam a própria efetividade dos demais direitos fundamentais.

A alteridade, pautada na moralidade da relação entre os homens e no reconhecimento do "outro", portanto, deve nortear o direito fundamental de propriedade e, através da alterlogia, restringi-lo quando necessário.

\section{REFERÊNCIAS}

ALEXY, Robert. Teoria dos direitos fundamentais. Tradução de Virgílio Afonso da Silva. São Paulo: Malheiros, 2008. Título original: Theorie der Grundrecht.

BITTAR, E. C. B. Reconhecimento e direito à diferença: teoria crítica, diversidade e a cultura dos Direito Humanos. Revista da Faculdade de Direito, Universidade de São Paulo, [S. 1.], v. 104, p. 551-565, 2009. Disponível em: <

https://www.revistas.usp.br/rfdusp/article/view/67869 >. Acesso em: 30 de junho de 2021.

COSTA, José André da. Ética e política em Levinas: alteridade, responsabilidade e justiça. Passo Fundo: IFIBE, 2013.

DESCARTES, René. Discurso do Método. 3. ed., ver. e ampl. São Paulo: Martins Fontes, 2007, P.33-34.

DI PIETRO, Maria Sylvia. Direito Administrativo. 25 ed. São Paulo: Atlas, 2012.

ENGELS, Friedrich. A origem da família, da propriedade privada e do Estado: em conexão com as pesquisas de Lewis H. Morgan. Tradução de Nélio Schneider. 1 ed. São Paulo: Boitempo, 2019. 
BORTOLOTI, José Carlos Kraemer; FLORES, Nilton Cesar. DIREITO E(M) ALTERIDADE: $o$ individualismo exacerbado e a abstração dos direitos humanos. Revista Direitos Fundamentais \& Democracia, v. 15, n. 15, p. 119-131, 2014. ISSN: 1982-0496.

FONSECA, Reynaldo Soares da. O princípio constitucional da fraternidade: seu resgate no sistema de Justiça. Belo Horizonte: Editora D’Plácido, 2019.

GONTIJO, Lucas de Alvarenga; ARCELO, Adalberto Antônio Batista. A biopolítica nos estados democráticos de direito: a reprodução da subcidadania sob a égide da constitucionalização simbólica. In: CONGRESSO NACIONAL DO CONPEDI, 18., São Paulo 2009. Anais... Disponível em: <http://www.publicadireito.com.br/ conpedi/manaus/arquivos/Anais/sao_paulo/2412.pdf>. Acesso em: 30 de julho de 2021.

GRAU, Eros Roberto. A ordem econômica na Constituição de 1988. 19 ed. Atual. São Paulo: Malheiros. 2018.

MICHAEL, Lothar e MORLOK, Martin. Direitos Fundamentais. Tradução de Antônio Francisco de Souza e Antônio Franco. 2 ed. São Paulo: Saraiva, 2016.

NEVES, Maria do Céu Patrão. Alteridade e Deveres Fundamentais: uma abordagem ética. Salvador: Revista Direitos Fundamentais e Alteridade, V. I No 01, p. 69 a 86, jul-dez, 2017.

PIEROTH, Bodo e SCHLINK, Bernhard. Direitos Fundamentais. Tradução de Antônio Francisco de Souza e Antonio Franco. 2 ed. São Paulo: Saraiva Educação, 2019.

PRATA, Ana. A tutela constitucional da autonomia privada. Lisboa: Almedina, 2017.

TAVARES NETO, José Querino; KOZICKI, Katya. DO “EU” PARA O “OUTRO”: A ALTERIDADE COMO PRESSUPOSTO PARA UMA (RE) SIGNIFICAÇÃO DOS DIREITOS HUMANOS. Revista da Faculdade de Direito UFPR, Curitiba, jun. 2008. ISSN 2236-7284. Disponível em: <https://revistas.ufpr.br/direito/article/view/15735>. Acesso em: 30 de junho de 2021. doi: http://dx.doi.org/10.5380/rfdufpr.v47i0.15735. 